\title{
Identificação de plantas tóxicas de interesse veterinário em assentamentos rurais do Agreste Meridional de Pernambuco, Brasil
}

Jaianne Keitt Alves de Melo, João Marcelo Cavalcante de Almeida, Marcos Pinheiro Franque, Luiz Carlos Fontes Baptista Filho, Taciana Rabelo Ramalho Ramos

Universidade Federal Rural de Pernambuco (UFRPE), Garanhuns, PE, Brasil

*Autor correspondente

e-mail: taciana.rrr@gmail.com

\section{Resumo}

Com o objetivo de identificar plantas tóxicas para ruminantes, em propriedades de assentamentos rurais do Agreste Meridional de Pernambuco, 89 propriedades nas cidades de Iati, Itaíba e Águas Belas foram inspecionadas no período de maio a outubro de 2015. Ao todo, foram reconhecidas 16 espécies de plantas tóxicas, verificados os locais de ocorrência e a quantidade da planta no locais. Mimosa tenuiflora (jurema preta) em 82,02\% (73/89) das propriedades visitadas; locais: capoeira (53/73), pastagem (40/73), mata (01/73) e em margens de rios, lagos e açudes (04/73); quantidade: alta em 27,40\% (20/73), moderada em 45,21\% (33/73) e baixa em 27,40\% (20/73). Prosopis juliflora (algaroba) em 78,65\% (70/89) das propriedades visitadas; locais: capoeira (46/70), margens de rios, lagos e açudes (17/70), e pastagem (40/70); quantidade: alta em 21,43\% (15/70), moderada em 41,43\% (29/70) e baixa em 37,14\% (26/70). Aspidosperma pyrifolium (pereiro) em 28,09\% (25/89) das propriedades visitadas; locais: capoeiras (22/25), mata (01/25) e pastagens (03/25); quantidade: alta em 28\% (07/25), moderada em 40\% (10/25) e baixa em 32\% (08/25). Piptadenea macrocarpa (angico preto) em 22,47\% (20/89) das propriedades visitadas; locais: capoeira (16/20) e (09/20) pastagem; quantidade: alta em 55\% (11/20), moderada em 30\% (06/20) e baixa em 15\% (03/20). Senna obtusifolia (mata pasto) em 21,35\% (19/89) das propriedades visitadas; locais: capoeira (04/19), margens de rios, lagos e açudes (05/19) e pastagem (13/19); quantidade: alta em 21,05\% (04/19), moderada em 43,37\% (09/19) e baixa em 31,58 (06/19). Amaranthus sp. (bredo) em $14,61 \%$ (13/89) das propriedades visitadas; locais: mata (01/07), capoeira (04/07), margens de rios, lagos e açudes (02/07), e pastagem (06/07); quantidade: alta em 42,86\% (03/07), moderada em 14,29\% (01/07) e baixa em 42,86\% (03/07). Tephrosia cinerea (falso anil) em 10,11\% (09/89) das propriedades visitadas; locais: capoeira (07/9), margens de rios, lagos e açudes (02/09), e pastagem (06/09); quantidade: alta em 22,22\% (02/09), moderada em 33,33\% (03/09) e baixa em 44,44\% (04/09). Lantana camara (chumbinho) 
em 10,11\% (09/89) das propriedades visitadas; locais: capoeira (06/09) e mata (03/09); quantidade: alta em 22,22\%, moderada em 11,11\% e baixa em 66,67\% (06/09). Além destas descritas acima, também foram observadas Senna occidentalis (fedegoso) e Sida carpinifolia (vassourinha) em 5,62\% (05/89) das propriedades visitadas, Solanum paniculatum (jurubeba) em 3,37\% (03/89), Ipomoea fistulosa (canudo), Centratherum brachylepis (perpétua) e Indigofera suffriticosa (anil) em 2,25\% (02/89), e Ricinus communis (mamona) em 1,12\% (1/89). A grande diversidade de plantas identificadas na região estudada, associada a longo períodos de estiagem, favorece a ocorrência de casos de intoxicação em ruminantes, com possibilidade de variados sinais clínicos. Assim, o desenvolvimento de ações direcionadas à capacitação dos produtores para identificação e controle de tais plantas podem minimizar as perdas advindas da intoxicação animal. 